\title{
Sources of Partial Resistance to Fusarium Root Rot in the Pisum Core Collection
}

\author{
N. J. Grünwald, V. A. Coffman, and J. M. Kraft, United States Department of Agriculture-Agricultural Research \\ Service, Washington State University-IAREC, Prosser 99350
}

\begin{abstract}
Grünwald, N. J., Coffman, V. A., and Kraft, J. M. 2003. Sources of partial resistance to Fusarium root rot in the Pisum core collection. Plant Dis. 87:1197-1200.

Fusarium root rot, caused by Fusarium solani f. sp. pisi, is one of the most important fungal diseases of pea and is found in most pea-growing areas around the world. Currently, no commercial cultivars are resistant to this pathogen. Availability of new sources of partial resistance could provide another tool for managing Fusarium root rot. In all, 387 accessions from the Pisum core collection were evaluated for resistance to Fusarium root rot in two independent experiments. Nonparametric analysis of variance conducted on ranks of disease severity for each accession indicated that the two experiments corresponded well. Forty-four plant introduction lines with a disease severity rating of 2.5 or less on a 0 -to- 5 scale (where $5=$ completely rotted) were selected as being partially resistant to root rot. Immunity to Fusarium root rot was not found. Comparison of disease resistance data for Aphanomyces root rot and Fusarium root rot showed a weak, but significant and positive correlation. A complete listing of the data for the partial resistance of all accessions tested can be found at the National Plant Germplasm System website, United States Department of Agriculture-Agricultural Research Service.
\end{abstract}

Additional keywords: Pisum sativum

Fusarium root rot, caused by Fusarium solani (Mart.) Sacc. f. sp. pisi (F. R. Jones) W. C. Snyder \& H. N. Hans, is an economically important fungal disease of pea (Pisum sativum L.) in most pea-growing areas around the world (6-8). Currently, no commercial cultivars are completely resistant to this pathogen. Fusarium root rot is managed by a combination of cultural practices, including tillage practices that avoid soil compaction and promote plant growth and use of high quality seed. Availability of new sources of genetic resistance could enhance the use of plant resistance as another tool for managing this disease.

Germ plasm collections are an invaluable resource for discovery of novel sources of resistance to plant pathogens (12). The Pisum germ plasm collection, encompassing 3,615 accessions as of March 2002, is maintained by the Western Regional Plant Introduction Station (WRPIS), located at Washington State University in Pullman. This germ plasm collection has been characterized for resistance to several soilborne plant pathogens, including Fusarium wilt races 1 and 2

Corresponding author: N. J. Grünwald

E-mail: ngrunwald@pars.ars.usda.gov

Accepted for publication 9 May 2003.

Publication no. D-2003-0721-03R

This article is in the public domain and not copyrightable. It may be freely reprinted with customary crediting of the source. The American Phytopathological Society, 2003. (caused by $F$. oxysporum f. sp. pisi) and Aphanomyces root rot (caused by Aphanomyces euteiches Drechs.) (10,11). Since 1996, the United States Department of Agriculture-Agricultural Research Service (USDA-ARS) research program has been characterizing accessions for resistance to Fusarium root rot. Characterization of the Pisum core collection for resistance to Fusarium root rot should provide data on the degree of partial resistance available and should identify novel sources of partial

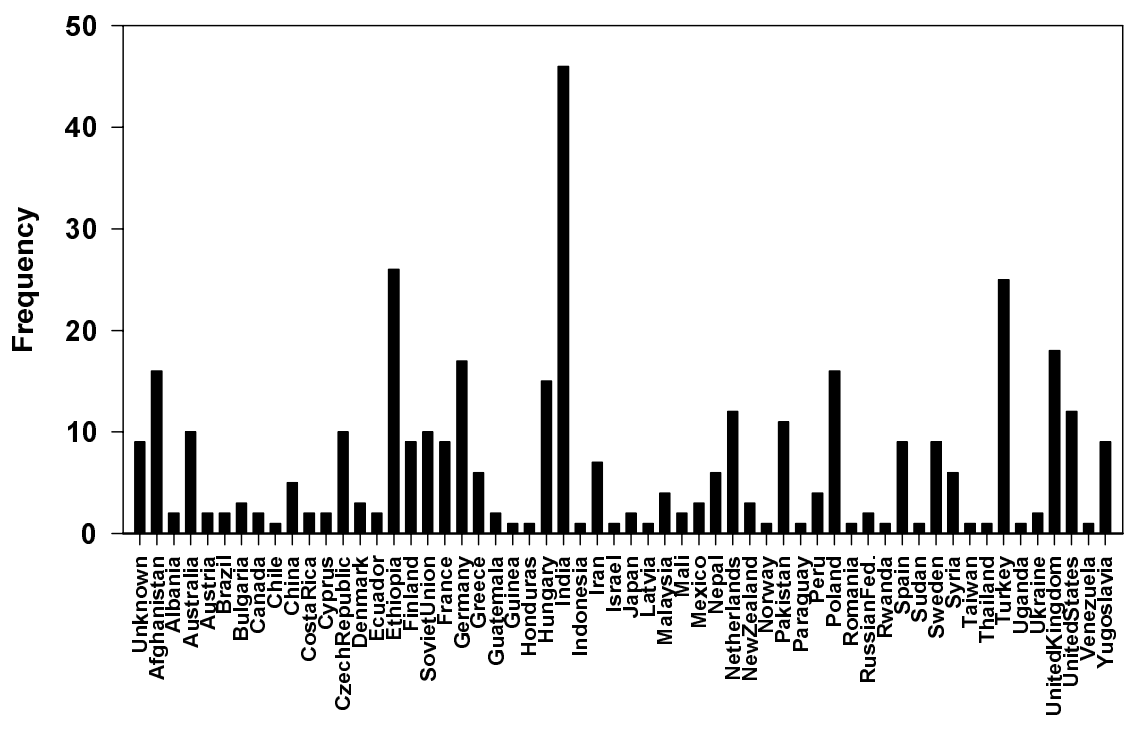

Country of origin

Fig. 1. Histogram of number of accessions from a subsample of the Pisum core collection evaluated by country of origin. Nine accessions were of unknown origin. resistance that may be useful in breeding programs.

Our objective was to identify sources of partial resistance against Fusarium root rot available in the Pisum core collection. The Pisum core collection is composed of 504 accessions from 57 countries, representing about $17 \%$ of pea accessions, and was designed to include accessions based upon documented concentrations of diversity and the entire range of adaptation (16). We evaluated 387 plant introduction (PI) accessions for resistance to Fusarium root rot in two independent greenhouse experiments. We also tested the hypothesis that accessions that are partially resistant to Fusarium root rot are also resistant to Aphanomyces root rot, using Aphanomyces root rot data available from the WRPIS website and the literature (10).

\section{MATERIALS AND METHODS}

Seed source. Due to seed availability, a subsample of 387 PI accessions of the 504 accessions in the Pisum core collection were obtained from the USDA WRPIS, Pullman, WA. The accessions were of diverse origin and originated from 57 countries as well as unknown locations (Fig. 1) (16). In addition to $P$. sativum, which made up $93 \%$ of accessions, several subspecies of $P$. sativum were included (Table 1). 
Inoculum. Isolates of $F$. solani $\mathrm{f}$. sp. pisi for these experiments were maintained in 10 $\mathrm{g}$ of a 1:1:1 soil:peat moss:perlite mixture that was crushed, mixed, and autoclaved in test tubes and stored at $5^{\circ} \mathrm{C}(17)$. A conidial suspension from a heavily sporulating, fresh culture in $2 \mathrm{ml}$ of Kerr's medium (2) was delivered to soil mix and air dried to induce chlamydospore formation.

For each series of greenhouse experiments, the same five isolates were reiso- lated on peptone-pentachloronitrobenzene (peptone-PCNB) agar by sprinkling a few soil grains on the agar (14). Individual 250-ml Erlenmeyer flasks containing 120 $\mathrm{ml}$ of Kerr's medium were inoculated with a 2-mm agar plug of the three best-growing isolates randomly selected from the five isolates grown on peptone-PCNB. Flasks were placed on an orbital shaker under 24$\mathrm{h}$ light at room temperature for 6 days. Conidia were collected by straining cul-

Table 1. Frequency of species in subsample of core collection evaluated for partial resistance to Fusarium root rot

\begin{tabular}{lcc}
\hline Taxon & Frequency & Percent \\
\hline Pisum sativum & 361 & 93.3 \\
P. sativum subsp. abyssinicum & 4 & 1.0 \\
P. sativum subsp. elatius & 5 & 1.3 \\
$P$. sativum subsp. sativum & 15 & 3.9 \\
$P$. sativum var. arvense & 2 & 0.5 \\
Total & 387 & 100.0 \\
\hline
\end{tabular}
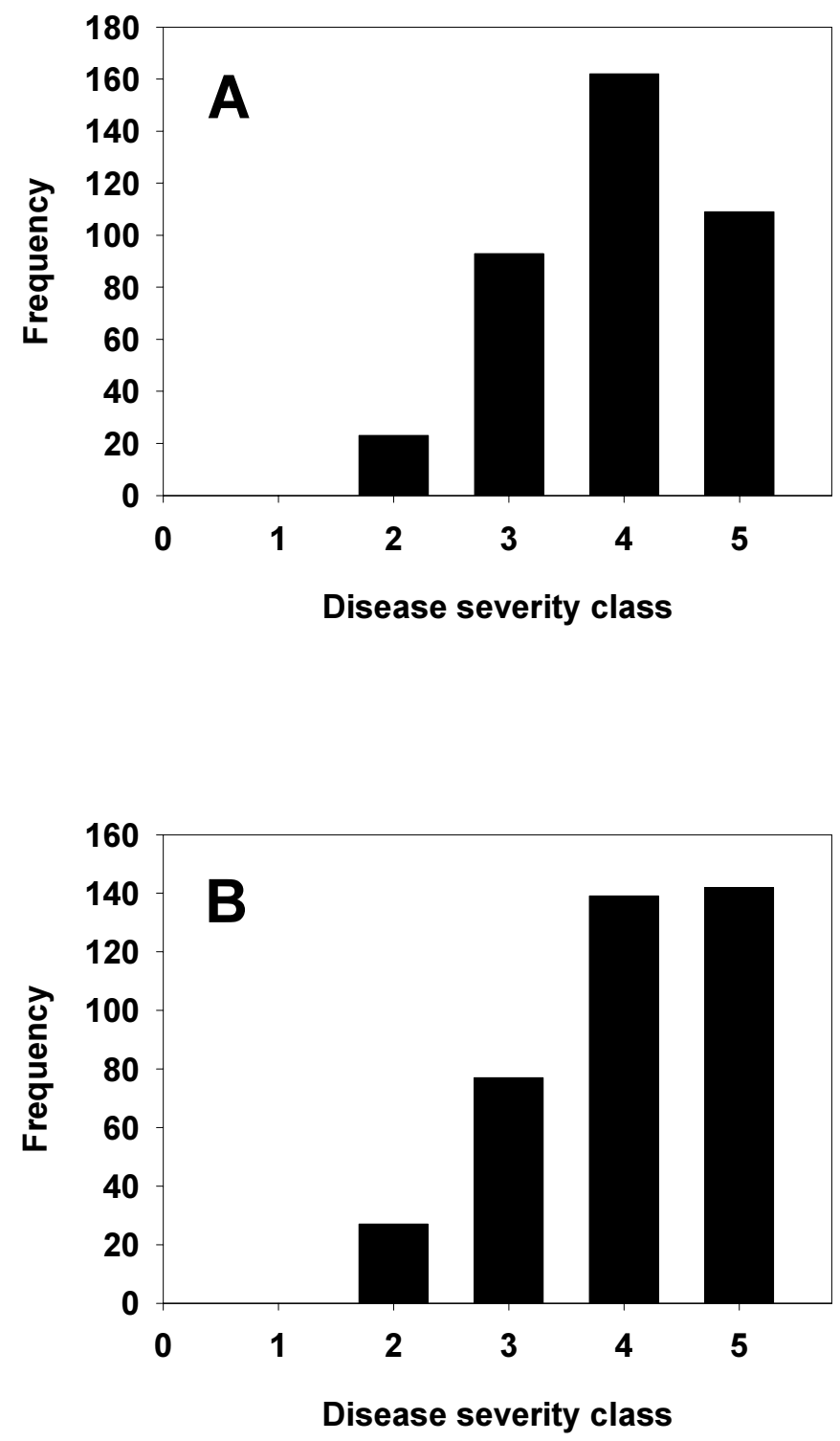

Fig. 2. Histogram displaying the distribution of accessions in each disease severity class in $\mathbf{A}$, first, and $\mathbf{B}$, second experiment $(\mathrm{n}=387)$. Disease severity was scored visually on a scale of 0 (= no disease) to 5 (= completely rotten) on uprooted and washed roots. tures through sterile cheesecloth. Strained suspensions of conidia for each of the three isolates of $F$. solani were combined and concentration of conidia was adjusted to $10^{6}$ spores $\mathrm{ml}^{-1}$. Inoculum was kept chilled $\left(4^{\circ} \mathrm{C}\right)$ until use later the same morning.

Greenhouse experiments. Seed of a few accessions had to be scarified using a razor blade. Seed of each accession was inoculated by soaking seed in 50 to $60 \mathrm{ml}$ of a conidial suspension in 100-ml beakers at room temperature overnight. Ten seed of each accession were planted after inoculation in single rows in plastic trays $(27.3 \times$ $51.1 \times 6.4 \mathrm{~cm} \mathrm{[10} \mathrm{3/4} \mathrm{by} 201 / 8$ by $21 / 2$ in.]; Landmarks, Akron, $\mathrm{OH}$ ) with perlite in two replications per experiment. Three accessions were planted per tray. Two independent experiments were conducted in 1996 and 2001. Cv. Dark Skin Perfection was the susceptible control for each experiment. Plants were harvested after 20 days and roots were scored on a 0-to-5 scale, where $0=$ no symptoms; $1=$ slight hypocotyl lesions; 2 = lesions coalescing around epi- and hypocotyl; 3 = lesions starting to spread into the root system, with root tips starting to be infected; $4=$ epicotyl, hypocotyl, and root system almost completely infected and only slight amount of white, uninfected tissue left; and $5=$ completely infected root (5).

Data analysis. Greenhouse experiments followed a completely randomized design with two replications per accession. A mean disease severity score was given as an average over all 10 seedlings planted for each replication. Nonparametric statistics were used for data analyses because disease severity data were nonnormally distributed. To assess whether accessions evaluated in independent experiments resulted in the same ranking of accessions (i.e., no significant differences of median disease severity by accession among the two experiments), a nonparametric analysis of variance (ANOVA) based on ranks was conducted (1): first, ranks were assigned to all observations using PROC RANK (SAS User's Guide: Statistics; SAS Institute, Cary, NC) and, second, ranks were subjected to ANOVA using PROC ANOVA. Selections for the best accessions were arbitrarily made at a disease severity rating less than or equal to 2.5 .

To assess whether resistance to Aphanomyces root rot and Fusarium root rot are related, data for Aphanomyces root rot submitted by D. K. Malvick to GRIN was obtained online (10). Downloaded data for Aphanomyces root rot is given in percent damage to plants. A Spearman rank correlation coefficient between Aphanomyces and Fusarium root rot scores was calculated using PROC FREQ.

\section{RESULTS}

Two independent experiments were conducted to evaluate partial resistance and the results indicate that the two experi- 
ments yielded qualitatively similar results. Nonparametric ANOVA conducted on ranks of disease severity for each accession rejected the hypothesis that there were significantly different rankings among accessions in the first and second experiment $(P=0.9447)$.

Good levels of partial resistance to Fusarium root rot were identified, but disease severity scores for accessions ranged between 1.5 and 5, while most accessions had a disease severity score of 3 to 5 (Fig. 2 ). Forty-four accessions with very high partial resistance were identified in the Pisum core collection (Table 2). These accessions consistently scored below or equal to 2.5 on a 0 -to- 5 disease severity scale. Of the best accessions, 2, 7, 14, and 21 accessions scored a mean disease severity value of $1.75,2,2.25$, and 2.5 , respectively (Table 2). The standard deviation of severity on each of these accessions was less than 1, except for three accessions (Table 2). Although most of the accessions presented in Table 2 were $P$. sativum, two were $P$. sativum subsp. sativum and one was $P$. sativum var. arvense. In general, accessions scoring below 3 were only found in P. sativum, $P$. sativum subsp. sativum, and $P$. sativum var. arvense (Fig. 3). The low number of accessions could confound this result for some of the taxa (Table 1).

Aphanomyces and Fusarium root rot data were significantly and positively correlated. The Spearman rank correlation was low at $r_{\mathrm{s}}=0.25(Z=4.9 ; P<0.001)$, but a large dataset of 344 observations still resulted in a significant correlation.

\section{DISCUSSION}

Several accessions of $P$. sativum with good levels of partial resistance to Fusarium root rot were identified. Forty-four accessions had a disease severity rating of
2.5 or less, with a standard deviation of less than or equal to 1.4. Only a few accessions from the PI collection previously evaluated were reevaluated in this project. Of the accessions shown in Table 2, PI164971 was previously scored as resistant, whereas PI166084, PI174921, and PI197990 were scored as 0.4, 1.5, and 3.0, respectively, on a 0 -to-5 scale $(3,4)$.

The methodology used for testing pea accessions for partial resistance to Fusarium root rot gave very repeatable results. This is supported by the good correspondence in rankings of accessions in the first and second experiment. A seed-soak inoculation method was used in this study and may have contributed to consistency of results. Inoculation procedures for other studies included growing test lines in infested soil (4) and spraying inoculum on seed at the time of planting (9). The methodology used in this study also was effi-

Table 2. Plant introduction (PI) accessions scoring less than or equal to 2.5 on a 0 -to- 5 disease severity scale ${ }^{\mathrm{a}}$

\begin{tabular}{|c|c|c|c|c|c|c|}
\hline Accession & Species & Origin & Flower color ${ }^{\mathbf{b}}$ & $\begin{array}{c}\text { Seed } \\
\text { pigmentation }\end{array}$ & $\begin{array}{c}\text { Mean disease } \\
\text { severity }\end{array}$ & $\begin{array}{l}\text { Standard } \\
\text { deviation }\end{array}$ \\
\hline PI203064 & P. sativum & Finland & $\mathrm{p}$ & $\ldots$ & 1.75 & 0.4 \\
\hline PI220174 & P. sativum & Afghanistan & $\mathrm{p}$ & $\ldots$ & 1.75 & 0.4 \\
\hline PI102888 & P. sativum & $\ldots$ & $\mathrm{p}$ & $\mathrm{m}$ & 2 & 0.0 \\
\hline PI125839 & P. sativum & Afghanistan & $\mathrm{p}$ & $\mathrm{m}$ & 2 & 0.7 \\
\hline PI195020 & P. sativum & Ethiopia & $\mathrm{p}$ & $\mathrm{m}$ & 2 & 0.0 \\
\hline PI198735 & P. sativum & Afghanistan & $\mathrm{m}$ & $\mathrm{m}$ & 2 & 0.0 \\
\hline PI207508 & P. sativum & Afghanistan & $\mathrm{p}$ & $\mathrm{m}$ & 2 & 0.0 \\
\hline PI220189 & P. sativum & Afghanistan & $\mathrm{p}$ & $\ldots$ & 2 & 0.0 \\
\hline PI222117 & P. sativum & Afghanistan & $\mathrm{p}$ & $\ldots$ & 2 & 0.0 \\
\hline PI121976 & P. sativum & India & $\mathrm{p}$ & $\mathrm{m}$ & 2.25 & 0.4 \\
\hline PI125840 & P. sativum & Afghanistan & $\mathrm{p}$ & $\mathrm{n}$ & 2.25 & 0.4 \\
\hline PI138945 & P. sativum & Iran & $\mathrm{p}$ & $\mathrm{m}$ & 2.25 & 0.4 \\
\hline PI175226 & P. sativum & India & $\mathrm{p}$ & $\mathrm{m}$ & 2.25 & 0.4 \\
\hline PI180693 & P. sativum & Germany & $\mathrm{p}$ & $\mathrm{m}$ & 2.25 & 0.4 \\
\hline PI180695 & P. sativum & Germany & $\mathrm{p}$ & $\mathrm{m}$ & 2.25 & 0.4 \\
\hline PI180702 & P. sativum & Germany & $\mathrm{p}$ & $\mathrm{n}$ & 2.25 & 1.1 \\
\hline PI184128 & P. sativum & Yugoslavia & $\mathrm{p}$ & $\mathrm{m}$ & 2.25 & 0.4 \\
\hline PI204306 & P. sativum & Australia & $\mathrm{p}$ & $\ldots$ & 2.25 & 0.4 \\
\hline PI219705 & P. sativum & Pakistan & $\mathrm{p}$ & $\ldots$ & 2.25 & 0.4 \\
\hline PI222071 & P. sativum & Afghanistan & $\mathrm{p}$ & $\ldots$ & 2.25 & 0.4 \\
\hline PI223526 & P. sativum & Afghanistan & $\mathrm{p}$ & $\mathrm{m}$ & 2.25 & 0.4 \\
\hline PI227457 & $P$. sativum & Iran & p & $\mathrm{m}$ & 2.25 & 0.4 \\
\hline PI413686 & P. sativum & Hungary & $\mathrm{p}$ & $\mathrm{m}$ & 2.25 & 0.4 \\
\hline PI1 16056 & P. sativum subsp. sativum & India & $\mathrm{p}$ & $\mathrm{m}$ & 2.5 & 0.0 \\
\hline PI1 16944 & P. sativum & Afghanistan & $\mathrm{p}$ & $\mathrm{m}$ & 2.5 & 0.0 \\
\hline PI163125 & P. sativum & India & $\mathrm{p}$ & $\ldots$ & 2.5 & 0.0 \\
\hline PI164612 & P. sativum & India & $\mathrm{m}$ & $\ldots$ & 2.5 & 0.7 \\
\hline PI166084 & P. sativum & India & $\mathrm{p}$ & $\ldots$ & 2.5 & 0.7 \\
\hline PI197450 & P. sativum & Ethiopia & $\mathrm{p}$ & $\ldots$ & 2.5 & 0.7 \\
\hline PI197990 & P. sativum & Netherlands & $\mathrm{p}$ & $\ldots$ & 2.5 & 0.7 \\
\hline PI215766 & P. sativum & Peru & $\mathrm{w}$ & $\mathrm{m}$ & 2.5 & 1.4 \\
\hline PI223527 & P. sativum & Afghanistan & $\mathrm{p}$ & $\mathrm{m}$ & 2.5 & 0.7 \\
\hline PI226561 & P. sativum & Ethiopia & $\mathrm{p}$ & $\ldots$ & 2.5 & 0.7 \\
\hline PI226564 & P. sativum & Ethiopia & $\mathrm{p} / \mathrm{m}$ & $\mathrm{m}$ & 2.5 & 0.7 \\
\hline PI227258 & P. sativum & Iran & $\mathrm{p}$ & $\mathrm{m}$ & 2.5 & 0.0 \\
\hline PI244121 & P. sativum & Netherlands & $\mathrm{w}$ & $\ldots$ & 2.5 & 1.4 \\
\hline PI249645 & P. sativum & India & $\mathrm{p}$ & $\ldots$ & 2.5 & 0.7 \\
\hline PI251051 & P. sativum & Yugoslavia & $\mathrm{p} / \mathrm{w}$ & $\mathrm{m}$ & 2.5 & 0.0 \\
\hline PI253968 & $P$. sativum & Afghanistan & $\mathrm{p}$ & $\ldots$ & 2.5 & 0.7 \\
\hline PI257592 & P. sativum & Ethiopia & $\mathrm{p}$ & $\mathrm{m}$ & 2.5 & 0.0 \\
\hline PI268480 & P. sativum var. arvense & Afghanistan & $\mathrm{p}$ & $\ldots$ & 2.5 & 0.0 \\
\hline PI271119 & P. sativum & Mali & $\mathrm{p}$ & $\ldots$ & 2.5 & 0.7 \\
\hline PI272194 & P. sativum & Germany & $\mathrm{p}$ & $\ldots$ & 2.5 & 0.0 \\
\hline PI505122 & P. sativum subsp. sativum & Albania & $\mathrm{p}$ & $\mathrm{m}$ & 2.5 & 0.7 \\
\hline
\end{tabular}

\footnotetext{
${ }^{a}$ Data for origin, flower color, and seed pigmentation were obtained from GRIN.

${ }^{b}$ Abbreviations: $\mathrm{m}=$ mixed, $\mathrm{p}=$ pigmented, and $\mathrm{w}=$ white flower color; $\mathrm{p} / \mathrm{m}=$ GRIN reports both pigmented and mixed score for flower color; $\mathrm{p} / \mathrm{w}=$ GRIN reports both pigmented and white score for flower color.

c $\ldots$ = Data not available in GRIN; $\mathrm{m}=$ mixed, $\mathrm{n}=$ nonpigmented green $/$ white seed coat.
} 


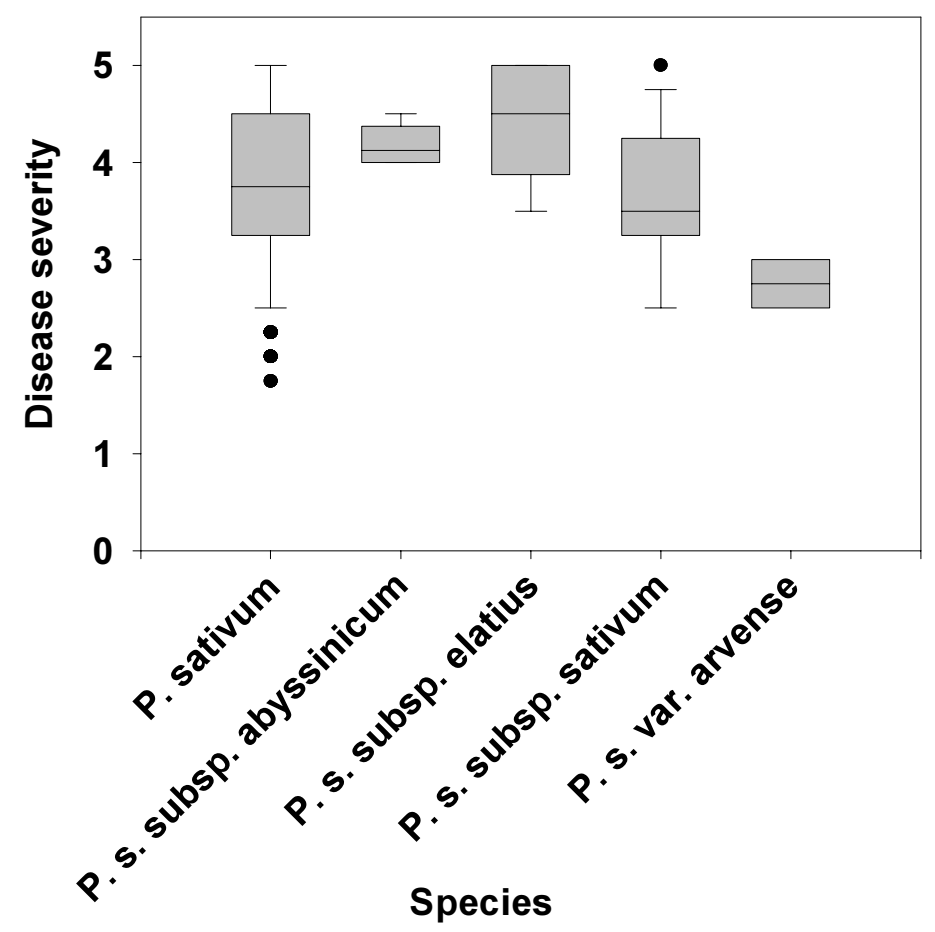

Fig. 3. Box plots of disease severity by subspecies of Pisum sativum evaluated for partial resistance to Fusarium root rot. The rectangles show the values below which 25\% (lower side of box), 50\% (the center line), and $75 \%$ (upper side of box) of the observations fall. The whiskers extending below and above the box represent the 5th and 95th percentiles, respectively. Dots represent outlying data points located beyond the 5 th or 95 th percentile.

cient in terms of cost and labor requirements and can be recommended for use in breeding programs.

Prior research indicated that PI accessions found to be partially resistant against Fusarium root rot were lavender-flowered with pigmented seed (4). In the current study, two accessions found to be resistant had white (PI215766 and PI244121) and two had mixed (PI198735 and PI164612) flower color (Table 2). Two additional accessions, PI226564 and PI251051, were reported in GRIN with a mixed score as either being pigmented/mixed or pigmented/ white in flower color (Table 2). Two accessions found to be resistant had a nonpigmented white/green seed coat (PI125840 and PI180702). Thus, this study provides evidence that partial resistance to Fusarium root rot might not be linked to pigmented flower color and pigmented seed coats.

Comparison of disease data for Aphanomyces root rot (10) and Fusarium root rot showed a weak, positive correlation that was significant, primarily due to the large dataset (344 observations). Resistance to both diseases is likely based on several genes or single genes (QTLs) conferring quantitative resistance (9). Several QTLs for resistance to Aphanomyces root rot recently have been identified (15). A previous report indicated that resistance to $P y$ thium ultimum and $F$. solani may be conditioned by the same multiple, genetic factors (13). The Spearman rank correlation of $r=0.25$ between Aphanomyces and Fusarium root rots indicates that there is a relationship, but that it is not very strong.

This study identified 44 accessions in the Pisum core collection that show good partial resistance against Fusarium root rot. A complete listing of the data for the partial resistance of all accessions tested can be found at the National Plant Germplasm System website, USDA-ARS.

\section{ACKNOWLEDGMENTS}

We thank C. Coyne and the personnel at the USDA WRPIS for providing seed and passport data of the Pisum collection, and K. McPhee and W. Chen for their thoughtful comments and suggestions for improving the manuscript.

\section{LITERATURE CITED}

1. Eskridge, K. M. 1995. Statistical analysis of disease reaction data using nonparametric methods. HortScience 30:478-481.

2. Kerr, A. 1963. The root rot Fusarium wilt complex of peas. Aust. J. Biol. Sci. 16:55-69.

3. King, T. H., Johnson, H. G., Bissonnette, H. L., and Haglund, W. A. 1960. Development of lines of Pisum sativum resistant to Fusarium root rot and wilt. Proc. Am. Soc. Hortic. Sci. 75:510-516.

4. Kraft, J. M. 1975. A rapid technique for evaluating pea lines for resistance to Fusarium root rot. Plant Dis. Rep. 59:10071011.

5. Kraft, J. M., and Boge, W. 2001. Root characteristics in pea in relation to compaction and Fusarium root rot. Plant Dis. 85:936-940.

6. Kraft, J. M., Haware, M. P., and Hussein, M. M. 1988. Root rot and wilt disease of food legumes. Pages 565-575 in: World Crops: Cool Season Food Legumes. R. J. Summerfield, ed. Kluwer Academic Press, Boston.

7. Kraft, J. M., Larsen, R. C., and Inglis, D. A. 1996. Diseases of pea. Pages 325-370 in: The Pathology of Food and Pasture Legumes. D. Allen, ed. CAB International, Wallingford, UK.

8. Kraft, J. M., and Pfleger, F. L. 2001. Compendium of Pea Diseases and Pests. Second ed. The American Phytopathological Society, St. Paul, MN.

9. Lockwood, J. L. 1960. Progress and problems in breeding peas resistant to root rots. Mich Q. Bull. 43:358-366.

10. Malvick, D. K., and Percich, J. A. 1999. Identification of Pisum sativum germ plasm with resistance to root rot caused by multiple strains of Aphanomyces euteiches. Plant Dis. 83:51-54.

11. McPhee, K. E., Tullu, A., Kraft, J. M., and Muehlbauer, F. J. 1999. Resistance to Fusarium wilt race 2 in the Pisum core collection J. Am. Soc. Hortic. Sci. 124:28-31.

12. Muehlbauer, F. J. 1992. Use of introduced germplasm in cool-season food legume cultivar development. Pages 49-73 in: Use of Plant Introductions in Cultivar Development Part 2. H. L. Shands and L. E. Weisner, eds. Crop Science Society of America, Madison, WI.

13. Muehlbauer, F. J., and Kraft, J. M. 1973. Evidence of heritable resistance to Fusarium solani f. sp. pisi and Pythium ultimum in peas. Crop Sci. 13:34-36.

14. Nash, S. M., and Snyder, W. C. 1962. Quantitative estimations by plate counts of propagules of the bean root rot Fusarium in field soils. Phytopathology 52:567-571.

15. Pilet-Nayel, M. L., Muehlbauer, F. J., McGee, R. J., Kraft, J. M., Baranger, A., and Coyne, C. J. 2002. Quantitative trait loci for partial resistance to Aphanomyces root rot in pea. Theor. Appl. Genet. 106:28-39.

16. Simon, C. J., and Hannan, R. M. 1995. Development and use of core subsets of cool-season food legume germplasm collections HortScience 30:907.

17. Toussoun, T. A., and Nelson, P. E. 1968. A Pictorial Guide to the Identification of Fusarium Species According to the Taxonomic System of Snyder and Hansen. Pennsylvania State University Press, University Park. 